\title{
VISUAL DIAGNOSIS OF EYE DISEASES BY MEANS OF INFRA.RED RADIATION ${ }^{1}$
}

BY

\author{
A. VA ̌̌Ko and M. PELEŠKA \\ PRAGUE
}

LATELY we have been experimenting with image converters ${ }^{2}$ which are sensitive to infra-red radiation in an attempt to aid the diagnosis of certain diseases of the eye. We are studying normal as well as pathological tissues of the anterior and posterior parts of the eye and also investigating the possibility of seeing through opacities of all the component parts of the eye (cornea, aqueous humour, lens and vitreous humour).

For this purpose we measured the spectral transmission characteristics of these media. Fig. 1 shows the spectral distribution of transparence of a very opaque cornea and lens, the former

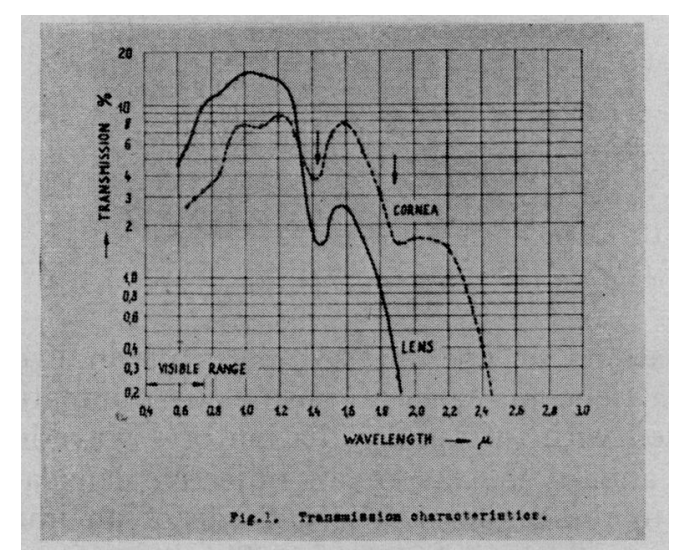

FIG. 1.

having been removed during a transplantation. The characteristic was measured on a double rocksalt monochromater shortly after the operation. Fig. 2 shows the same cornea before the operation in visible light and Fig. 3 in infra-red light. Various degrees of opacity of lenses and corneae resulted in non-uniform spectral transmission characteristics, but the transparence always increases as we move from the visible to the near infra-red region and measurements would indicate up to now a maximum of the transparence of opaque lenses in the region of wave-length $\lambda=10,000-12,000 \AA$. The arrows in the diagram indicate absorption bands of water. 




Fig. 2.



Fig. 3.

For observations of the anterior parts of an eye through an opaque cornea (leucoma corneae post ulcus traumaticum) the eye was illuminated with infra-red radiation of a wave-length exceeding $8,500 \AA$ and by means of an objective lens an image was projected on to the photo-electric cathode of an image converter with a long-wave limit of $14,000 \AA$. This image converter transforms the infra-red image of the observed eye on the cathode into a visible image on a fluorescent screen. This method of direct observation of the movable eye presents a number of advantages against photography on infra-red sensitive plates. We can simply focus by visual observation of the image on the fluorescent screen and photograph the image on the screen when the position of the eye is most suitable. Localisation in depth inside the eyt can be estimated by employing parallactic movement of the eye. Also we can use infra-red radiation of longer wavelength than can be used. in direct photography, because the long exposures involved in photography on infra-red sensitive plates render this process impracticable for the living eye; therefore the infra-red 
photographs which are known from literature all use merely the nearest parts of the infra-red spectrum. ${ }^{37}$

The infra-red image converter which we used had also been adapted for use in conjunction with the customary apparatus for ophthalmological diagnosis (Nordensen slit-lamp).

Observation in infra-red light proved to be especially useful as a complement to the conventional methods of ophthalmological diagnosis before transplantations of the cornea and similar, nowadays frequently performed operations.

\section{REFERENCES}

1. This preliminary report was read before a meeting of the Czechoslovak Ophthalmological Society, on December 13, 1946.

2. BUSCH-BRÜCHE. - Beiträge zur Elektronenoptik, p. 102, 1937.

3. Dekning.-Arch. f. Ophthal., Vol. CXXX, p. 373, 1933; Vol. CXXXIII, p. 20, 1935.

4. KUGelberg.-Acta Ophthal., Vol. X, 1932.

5. NORDENSEN.-Handbuch. d. biol, Arbeitsmethod, Vol. VI, 1934.

6. Dinz.-Caneja Bulletin de la Soc. Ophthal., 1936.

7. Lıjo Pavia, J.-Prem. Cong. Arg. Ophtal., October, 1936; in Arch. Oftal B.A.. Vol. XIII, November 11, p. 230, 1938.

\section{"THE RETICULO-ENDOTHELIAL SYSTEM OF THE CORNEA $" *+$}

BY

\section{Dr. Med. Tadeusz Krwawicz}

POLAND

THE results of investigations on colloidopectic properties of corneal cells are divergent. Whereas some writers as Blotevogel, 1924, Gasteiger, 1934, and others state that cells of the corneal stroma undoubtedly possess a colloidopectic ability, others as Loehlein, 1925, Jirman, 1936, did not succeed in confirming the observations of the above authors. Judging the question as one of far reaching theoretical and practical importance experiments were started on the permeability of cornea for some colloidal substances. Appropriate dye solutions and silver compounds were applied to the conjunctival sac. I attempted also to find those cells of the cornea which have the strongest properties of storing electronegative colloids, i.e., which cells of the cornea

- Received for publication, April 25, 1947.

† From the Eye Clinic of M. Curie-Skodowska University. Director: Professor Dr. I. Abramowicz. 